\title{
Factors governing the choice between repairing, strengthening, and reconstructing railway girder bridges
}

by

\author{
P. S. A. Berridge, M.B.E., M.I.C.E.
}

Mr F. R. L. Barnwell (Chief Civil Engineer, Western Region, British Railways) said that maintenance must always loom large in the mind of an engineer in charge of civil engineering assets or liabilities, particularly in a concern which had a long life such as British Railways.

67. In the opening paragraphs of the Paper the Author stated that Waddell had said, "The life of a metal bridge that is scientifically designed, honestly and carefully built, and not seriously overloaded, if properly maintained, is indefinitely long'. However normal a bridge was, some degree of compromise in its design and maintenance varied widely from good, conscientious work to neglect.

68. The analysis of the data concerning the under-bridges and past reconstructions and constructions had given an average estimated life of about 100 years for wrought iron and 85 years for the early steel. The modern steel design had a much longer life, for maintenance was taken very much into account. Fig. 23 showed the general picture of the life of bridges on the Western Region. On the left of the picture was a histogram showing the life of buildings up to 1962. Carrying on from there would be seen a dotted line which showed the time when all the previous bridges would come due for reconstruction. There was a peak in 1980-95 because of the telescoping of the steel and wrought iron bridges which were reaching the end of their life at the same time. It had been decided to flatten this curve out. It would not be possible to deal with such a peak of over 100 bridges a year for 16 years, with a maximum of 110 . Probably it would be impossible to cope with that with the present strength of the design staff--although the consulting engineers would no doubt be pleased to hear that. He did not know whether it would even be possible to construct the bridges with the aid of the steel industry.

69. Far more important, however, was the factor of occupation of the line. This could not possibly be faced. Consequently, it had been decided to reconstruct some a little prematurely, and this gave never more than 40 bridges a year, which was probably about the right number from the point of view of the programme of line occupation. This meant that many of the bridges being planned for reconstruction later would have to be repaired and examined much more carefully to avoid any risk of premature failure under traffic.

70. Fig. 24 showed a view of the East Largin Viaduct. In this and the adjoining St Pinnock Viaduct, the spans ranged between 40 and $65 \mathrm{ft}$ in length. They had originally been built in 1859 in timber and replaced in 1885 by wrought iron truss girder double-track spans. There were two main girders to each span with cross girders spanning between the vertical web members and carrying intermediate stringers. Transverse timber decking supported on the top chords of the main girders and on the stringers, carried the ballasted tracks. In 1960 examination had

* Proc. Instn civ. Engrs, vol. 26, September 1963, pp. 1-30. 
drawn attention to severe over-stressing, and it had been necessary to consider whether to reconstruct or to carry out major repairs. The major repairs were estimated to cost $£ 216000$ for the two double-line viaducts. Assessment of traffic requirements' had shown that the line could be singled over the two viaducts, a distance of about half a mile. This had made the problem much easier. The bridges had been strengthened by stiffening members of the truss girders and by duplicating the stringers-all without disturbing the timber decking-and the single track had been located along the middle of the spans. The whole work had been carried out without interruption to traffic except during the alterations to the permanent way. The cost had been brought down, including the signalling of the single line, to just over $£ 100000$.

71. It was necessary to keep a close eye on this sort of work, particularly in these days when the future of some lines was a little uncertain.

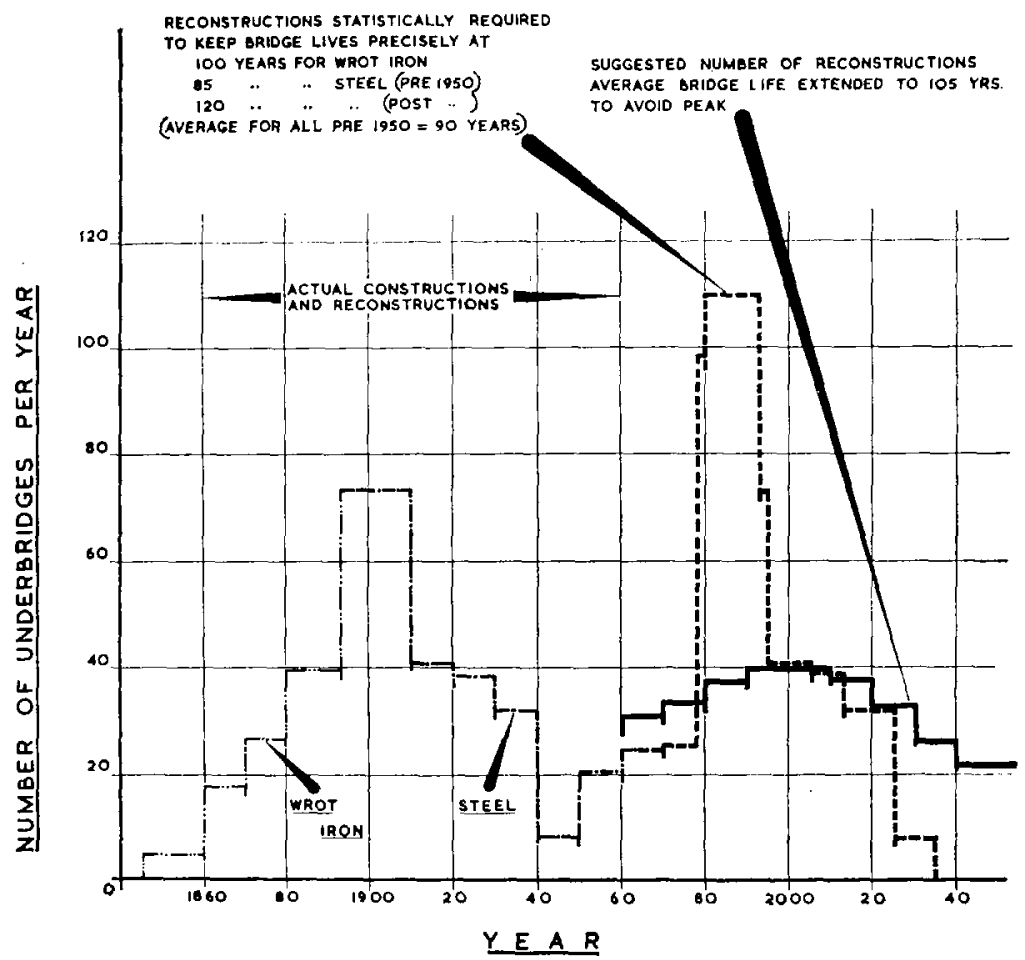

Fig. 23: British RaILWAys (W.R.) Underbridge Programme

Mr W. E. Gelson (Sir Bruce White, Wolfe Barry and Partners) said that in $\$ \S 20$ and 25-28 the Author outlined his practice for assessing the stresses in existing bridges giving certain multiplying factors for live load to cover impact and uncertainties of calculation.

73. Impact effect had come to include those effects which were due to track irregularities, rolling, and also hammer blow if steam locomotives were to be provided 


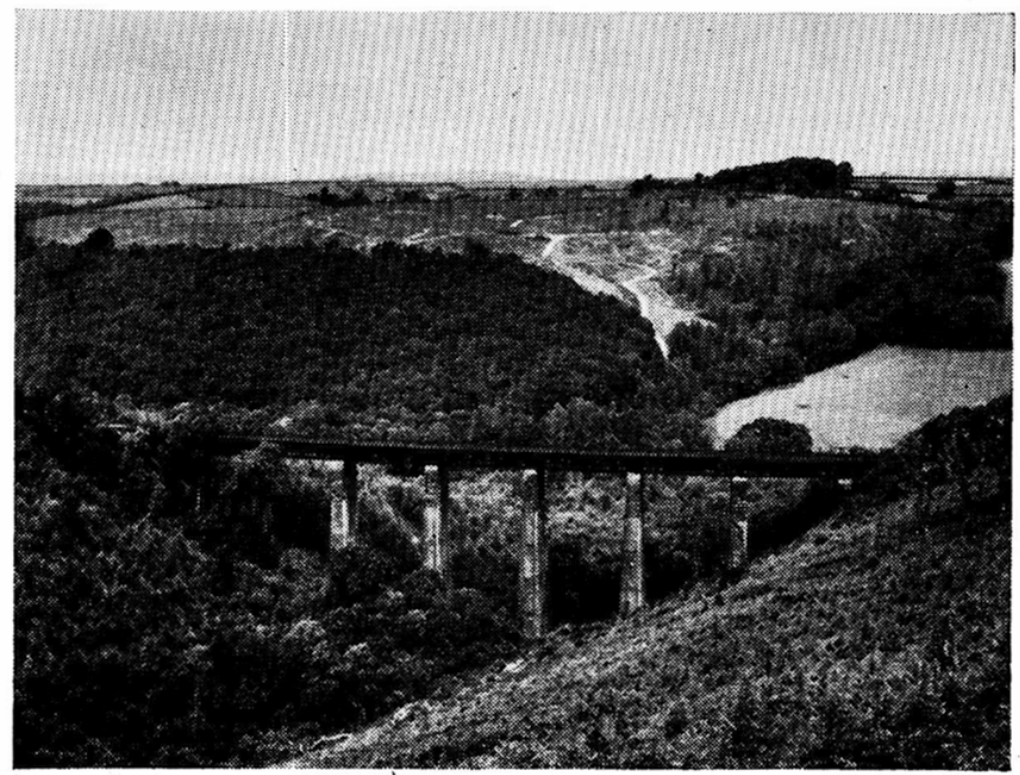

Fig. 24: View of East Largin Viaduct, British Railways (W.R.)

for. Were it not for dissipative forces the moving masses would induce oscillations in the span which were in practice suppressed by frictional resistance, at the ends of the span at bearings and in the permanent way.

74. A high or low rail joint caused elastic impulses to be applied to the bridge during the passage of successive wheels which could be important in a critical band of speeds on shorter spans and rail bearers. Also the rail head sometimes wore along its length to a wavy surface at the pitch of the sleeper spacing which could be important toward the end of the life of the rail.

75. Joint design commonly seen in France, particularly as regards sleeper density, appeared commendable to him. The Author would, he thought, confirm that successful results were obtained on Indian railways with close sleeper spacing at joints. The need for a stronger flsh-plate steel was appreciated and fish-plates in a steel with higher yield, combined with good fatigue resistance, were under trial in 1947. Rail joint design in Britain seemed to him to fall a little below the otherwise high standard of British track design and he thought that rail ends would need de-hogging as and when joints were welded.

76. An allowance had to be made for track irregularities in assessing the strength of floor members and main girders of small spans particularly when there was no cushion of ballast. No doubt that had been included in the overall factor for such cases.

77. Rolling or lurching effect was important in the case of deck bridges and rail bearers with tight road. It was small in main girders of through spans and on plain line because of the damping capacity of ballast and formation. Rolling phenomena were studied on several Indian railways during the early 'thirties. ${ }^{15}$ The N.W.R. had used a seismograph located on the vehicle. 

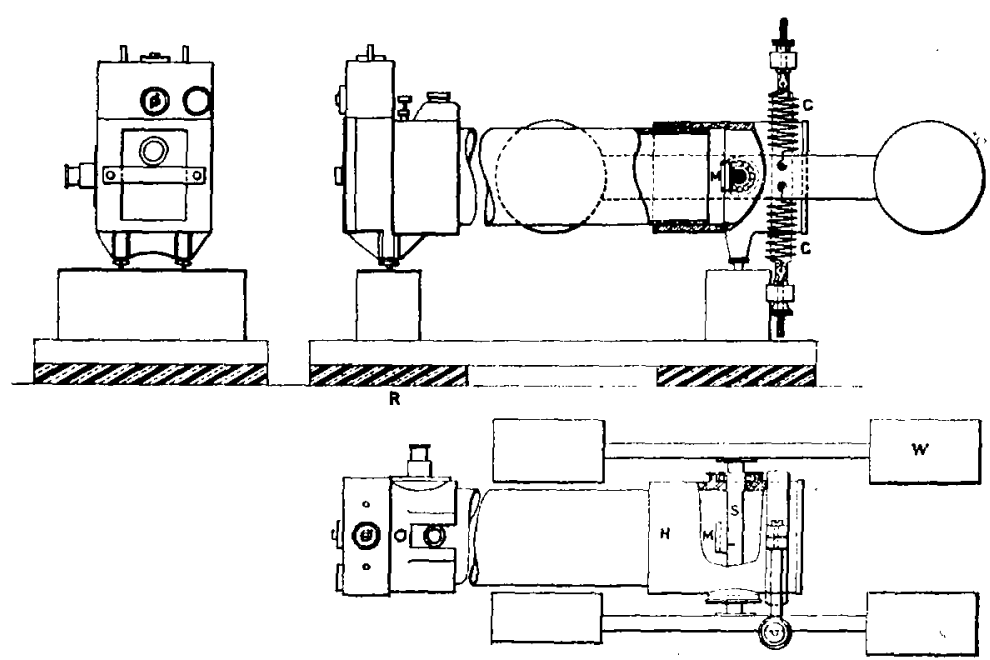

Fig. 25(a): Optical SEISMOgRaph FOR LURCh MEASUREMENTS, AS USED ON THE NorTh Western RaIlWay OF INDIA

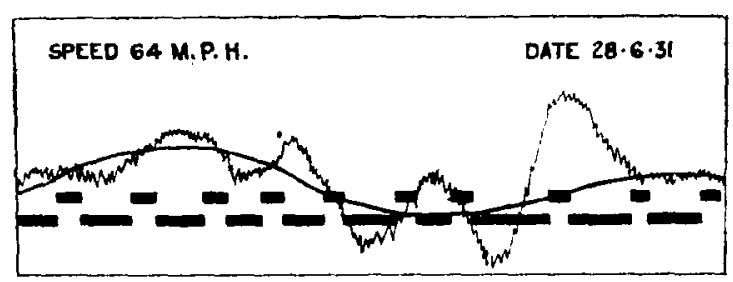

X.C. CLASS LOCO NO 1848

BRIDGE NO I5I NEAR LALAMUSA 23 SPANS 20́-"̈ CLEAR

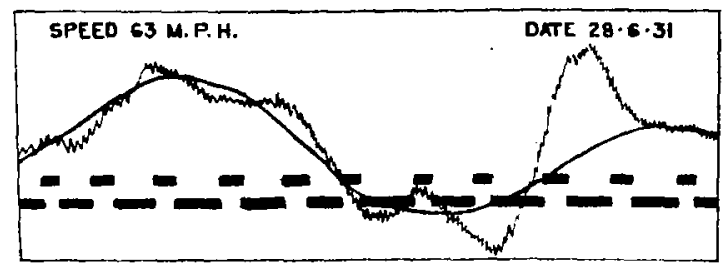

X.C. CLASS LOCO NO 1848

BRIDGE No 151 NEAR LALAMUSA 23 SPANS 20 -9̈ CLEAR

FiG. 25(b): EXAMPLES OF RECORDS OBTAINED FROM THE OPTICAL SEISMOGRAPH 
NORTH WESTERO RALWAY

LURCHING TESTS ON BRIDOES WITH BNDY PACKED APPROACHES

BRIOGE ME 151 MEAR LALAMUSA 23 SPANS $20^{\circ}-9^{\circ}$ CLEAR

X. E. CLASS LOCO NE 221

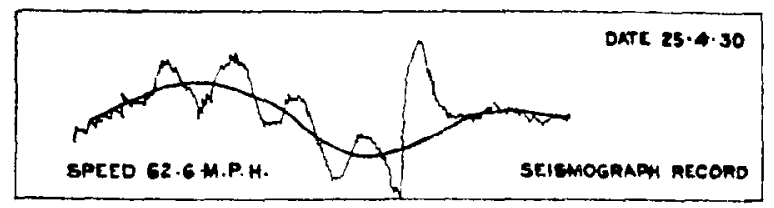

$\therefore$
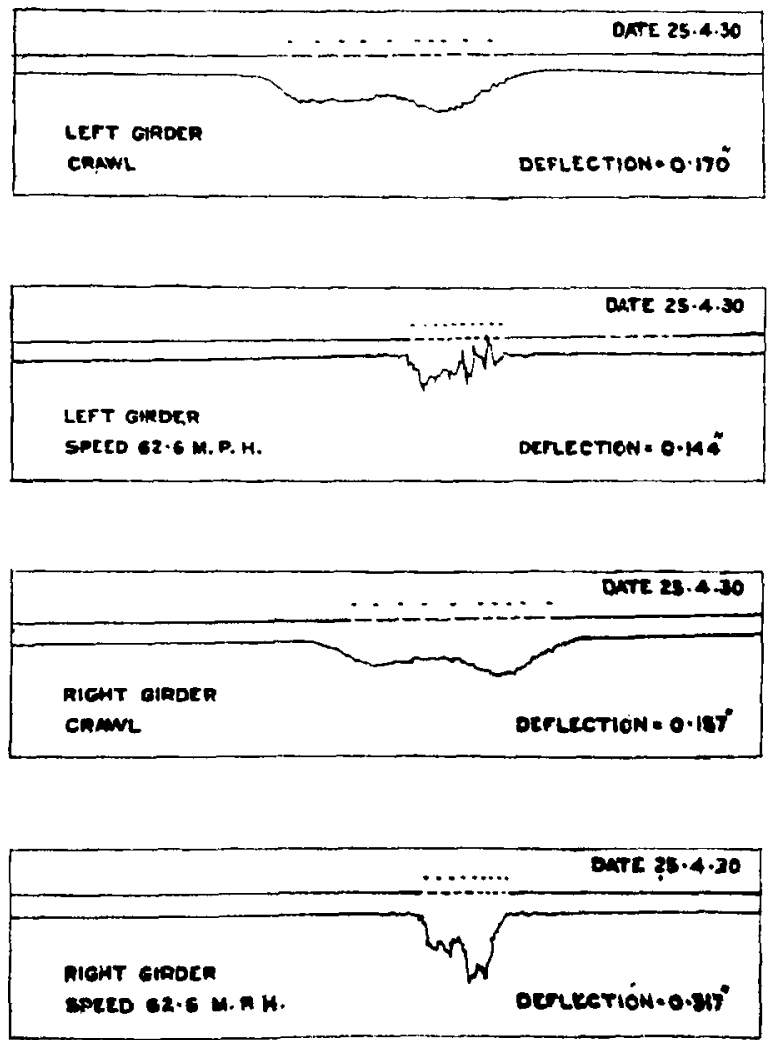

FIG. 26: EXAMPLES OF RECORDS OBTAINED FROM THE OPTICAL SEISMOGRAPH 
78. Fig. 25(a) showed a general arrangement. The camera portion of a FeredayPalmer stress recorder had a special head with a horizontal spindle carrying a spherical mirror. Masses attached to the spindle gave the oscillating system a suitable moment of inertia controlled by light springs to give a natural period of oscillation, large compared with the rolling period of the vehicle on its springs. Two records were shown in Fig. 25(b). The large half-waves on the right were recorded as the engine passed on to the bridge which had a moderately well-packed approach. The roll was negligible before the bridge was reached.

79. Fig. 26 referred to a test where a large error in cross levels was introduced at the bridge approach. The load was a 2-8-2. engine with $22 \frac{1}{2}$-ton axles, running light. The upper curve recorded roll and the lower ones the deflexion at the centre of the first span during the crawl and speed runs. Oscillation of the load persisted until it had crossed the bridge. The roll reached a peak value of more than $90 \%$ of the static wheel pressure and was, of course, an abnormal result.

80. Fig. 27 showed the machine used to study the stiffiness and damping characteristics of locomotive springs under pulsating loads. A paper on that investigation had been published by the Institution. ${ }^{16}$

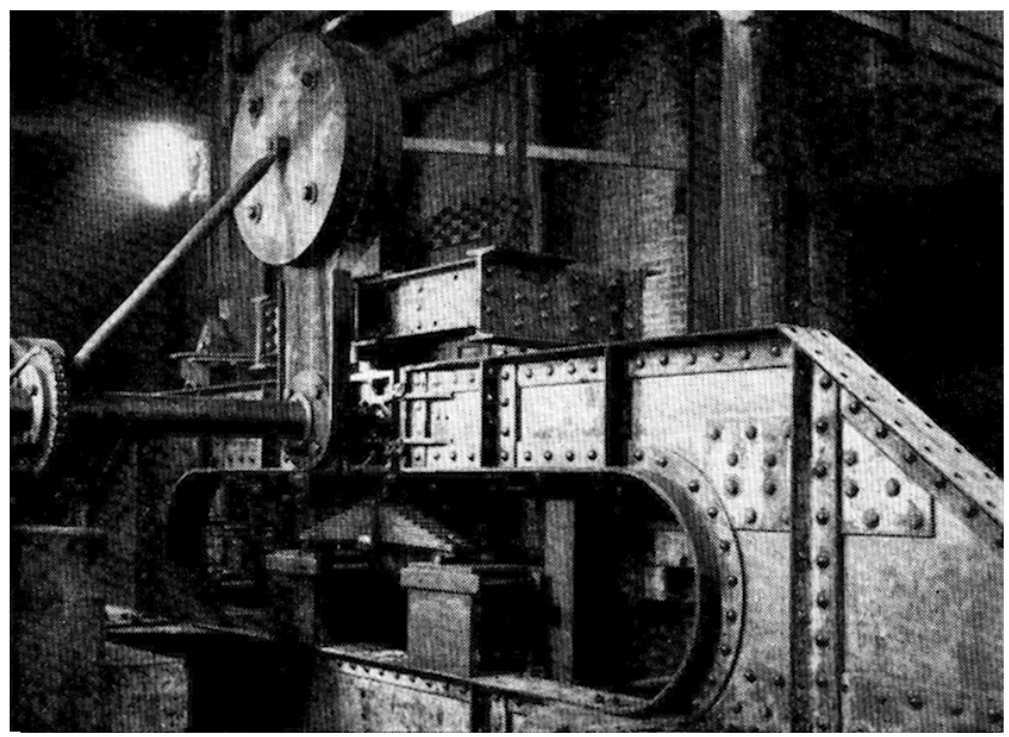

Fig. 27: SPRING-TESTING MACHINE

81. Fig. 28 summarized the results of the N.W.R. rolling tests. They were compared with the findings on other lines and a figure of $40 \%$ at $60 \mathrm{miles} / \mathrm{h}$ was adopted for roll on $5 \mathrm{ft} 6 \mathrm{in}$. gauge on deck spans and floors up to $60 \mathrm{ft}$ span. In assessing the strength of plate girders and rail bearers using simple methods of stress analysis, the Author included an intermediate factor to allow for the discrepancy commonly found between measured and calculated stresses.

82. He asked whether that intermediate factor was applied to dead as well as live load stress. That would be important in borderline cases where dead load was large. Measured deflexions of truss spans were usually found to be less than those 
determined by simple analysis, due in part to fixity of joints which gave rise to deformation stresses. Did the Author consider that the intermediate factor of unity provided adequate cover in the case of truss bridges? There was some relief due to interaction with lateral systems but that disappeared when $K$ laterals were used.

83. In the case of short plate girder spans, the discrepancy between measured stresses and those determined by simple analysis could usually be accounted for by end restraints and by relief offered by the permanent way. There were, however, cases where the full assumed relief was not available, such as in fish-belly plate girder spans, where the bearings were elevated near to the neutral plane of the bridge and in cases where the supports were flexible as in pile bridges. He would, therefore, suggest that the safer plan would be to keep the impact factor separate from the 'accuracy of calculation' factor and modify that as circumstances dictated.

84. The statistical method of analysis which had provided a basis for the impact factors given in the Author's Paper was obviously the best method when applied to

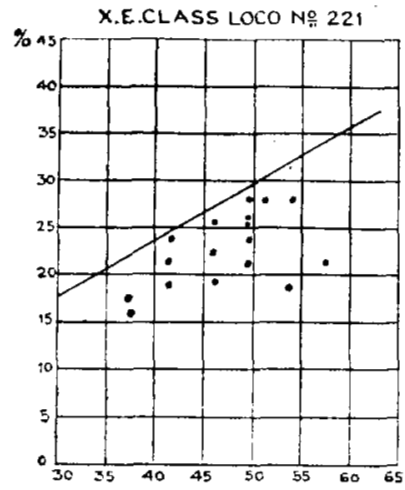

H.P.S CLASS LOCO NO 2868
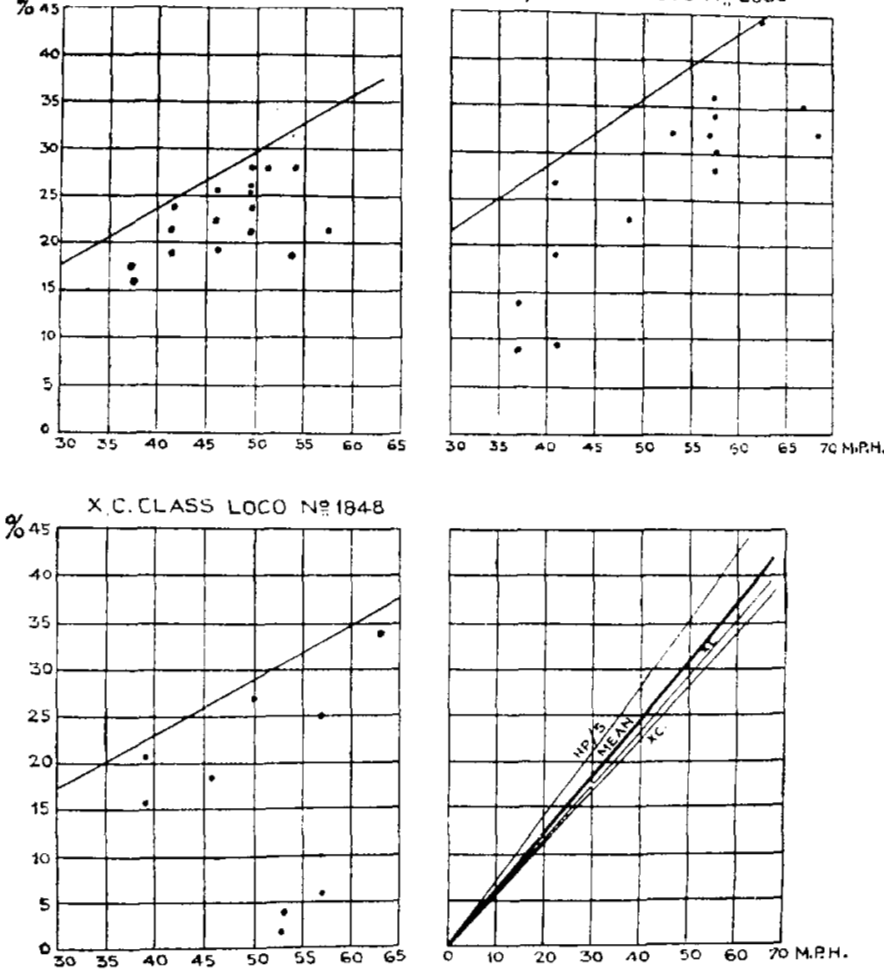

Fig. 28: RESULTS OBTAINED FROM LURCHING TESTS

Note: The values for lurch shown plotted here were obtained on short spans of various lengths with the permanent way in a moderate state of maintenance. Much higher values of lurch have been measured with track in a bad state of maintenance. 


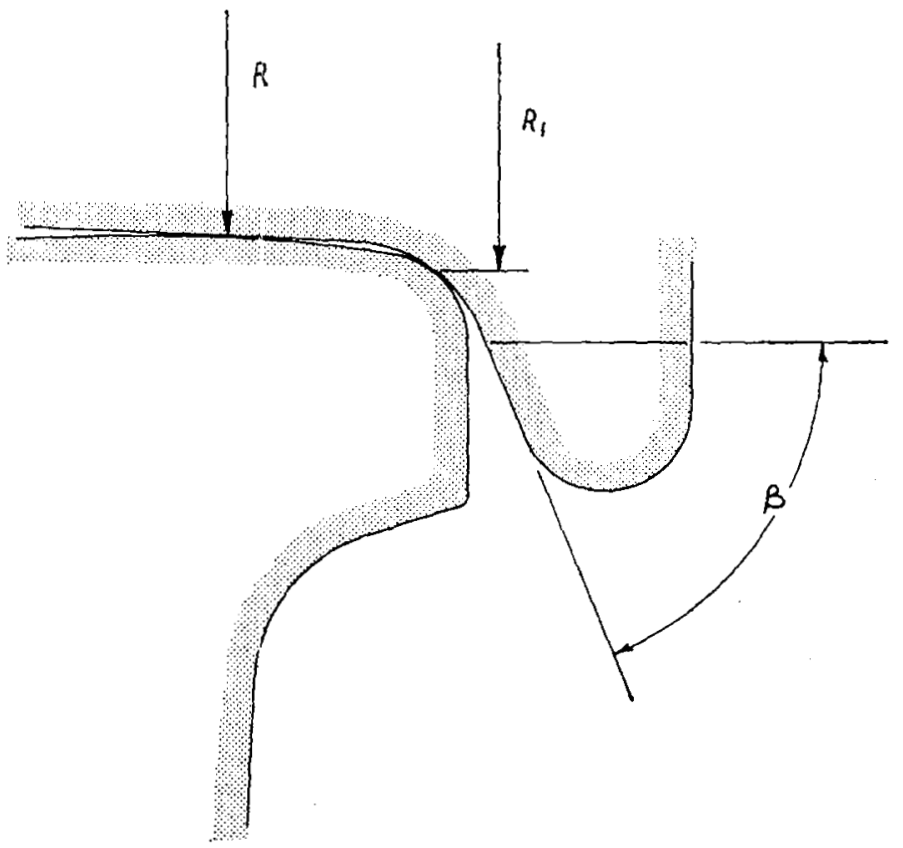

FIG. 29

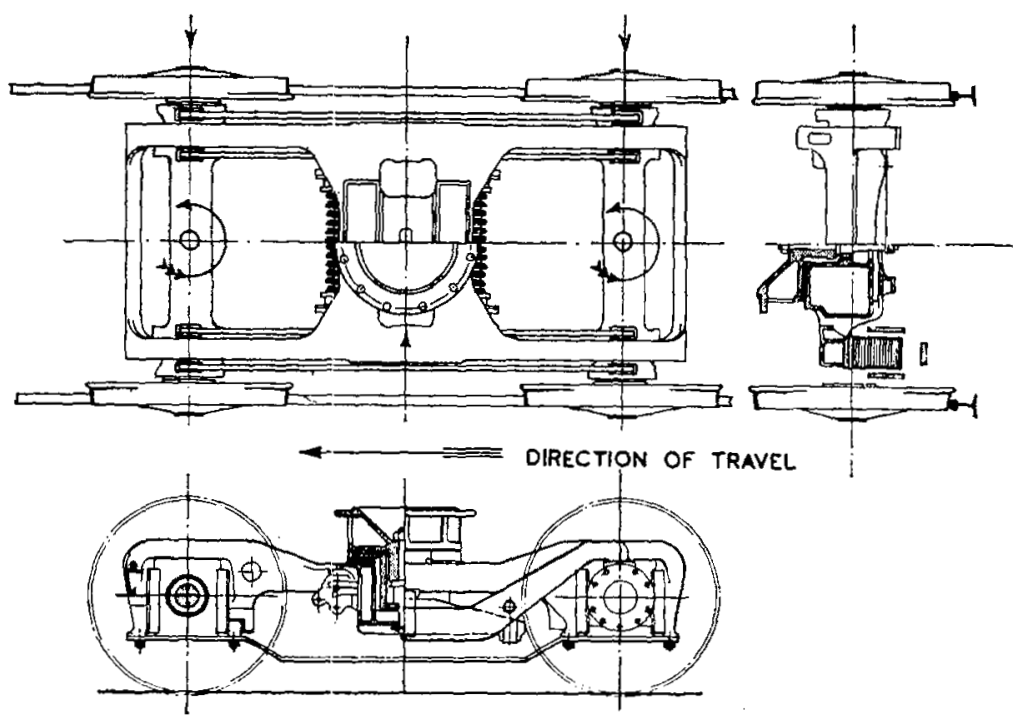

Fia. 30

16

Downloaded by [] on [26/04/23]. Copyright @ ICE Publishing, all rights reserved. 
bridge members, subject to many reversals and fluctuations of stress during the life of the bridge. Mr Gelson wanted the Author to give some more information about the types of span used in the tests and about the instrumentation. How was the gauge drift compensated for during the tests which must have extended over a long period?

85. In regard to the factors selected for impact, $1 \cdot 3$ had been chosen for truss members irrespective of span. Roll was unimportant in spans above $60 \mathrm{ft}$ and hammer-blow impact effect became unimportant in long spans. Why, therefore, had a constant factor been taken? Constant factors had been taken for main plate girders irrespective of whether they were of through or deck type, tight road or ballasted. Could an explanation be given for that?

86. Lateral loading induced by nosing was considered in $\$ \S 49-52$. Considerable investigation into the nosing problem was done on Indian railways during the period 1935-46, following a series of incidents involving track distortion and derailments. The experiments included tests on steam locomotives as well as two-axle freight stock. He would mention some of the deductions from those experiments.

87. Nosing and rolling were closely related phenomena associated with the solid railway wheel/axle assembly. The mechanical system consisted of the sprung and unsprung masses of the vehicle supported elastically by the track which also had a certain effective mass. There was quasi-elastic lateral constraint which came into play when the vehicle departed from purely longitudinal motion. If the tyres were turned to cylindrical profile, the period of lateral oscillation was not appreciably altered although the amplitude was reduced. The oscillation was maintained by the flange action.

88. A bogie performing a guiding function through gravity or spring controls was subjected at speeds above $50 \mathrm{miles} / \mathrm{h}$ to a periodic lateral disturbing force. It responded by following a sinuous and rotational path in the flange way clearances at the frequency of the disturbing force. The motion was such that the leading bogie axle reached its maximum lateral displacement in advance of the trailing axle by about $1 / 20$ of a complete period. The wheel pairs which at express speeds might be rotating at $12 \mathrm{rev} / \mathrm{s}$, had considerable rotational kinetic energy. As the leading wheel was forced towards the rail gauge face, by the control force and kinetic energy of the bogie, the tyre rode up on its flange root radius. Contact with the tread was superseded or supplemented by contact somewhere in the root radius (Fig. 29), which caused the axle to exert an anti-clockwise couple on the bogie frame, about a vertical axis. ${ }^{17}$ This was restrained by the trailing axle which at that stage was also exerting an anticlockwise couple for similar reasons. Fig. 30 illustrated the point.

89. In view of the short interval of time during which $R$ increased to $R_{1}$, Fig. 29, and because of the rotational kinetic energy stored in the wheel pair, slipping occurred at the contact faces. Longitudinal forces attaining an amount given by the product of wheel load, coefficient of dry sliding friction and $\sec \beta$ were applied to the tyres of the bogie wheels. The forces caused couples of like sign, the system of loading being as shown in Fig. 30.

90. Owing to the lateral flexibility of the rail and supports, this pattern of load distribution persisted for an appreciable period until contact was resumed at the railtable when the bogie had rotated and moved across the clearances until contact was made at the root radii of the other wheels of the bogie. The peak value of the flange pressure of the trailing wheel was found by experiment to be greater than that at the leading wheel.

91. In $\S 49$ the Author gave some data relating to the warship class of BoBo diesel locomotives. It appeared from the Indian experiments that the figure of 4.75 tons would be applicable as a point load to very short spans or rail-bearers, but for longer spans two loads of perhaps 4 tons spaced at the bogie axle centres would be appropriate.

92. It was interesting to note that in its natural mode of oscillation, the ends of the body of the Warship class were in anti-phase. That differed fundamentally from 
the mode of Indian locomotives or 2-axle wagons where the phase difference was more nearly a quarter period. The allowance of a single point load specified by B.S.153 was no doubt satisfactory for very short spans but not for longer ones.

93. Could the Author say whether the lateral loads quoted were recorded on plain line or on bridges? If it were the former, it seemed reasonable to expect that greater loads would have been recorded when crossing bridges.

Mr F. Turton (British Railways Board) said that in reading through the Paper he had come across one or two points of a more or less minor character to which he felt that he should draw attention.

95. In $\$ 18$ the impression might be gained that the examination of bridges on British Railways was left to the permanent way inspector. This was not the case. The code of examination provided that all bridges, with the exception of special structures, should be examined by bridge examiners every three years. The permanent way inspector played his part, but the principal point was that the bridge examiners were employed on this work.

96. $\$ 26 \mathrm{read}$ as follows:

'These permissible stresses were born of necessity following periods of enforced neglect during the war, and an urgency of avoiding restrictions to traffic.'

Mr Turton did not agree with this statement. These stresses had in fact been used by the staff of the pre-nationalization railway companies. They had been used for many years. But in many cases they had not been laid down in a fixed code as they were at present.

97. $\$ 37$ included the following:

-Although fatigue failure will be localized and its detection easy in a riveted bridge ...'

Mr Turton found this difficult to understand. He thought that insufficient information was known about fatigue in existing bridges, for a statement of that kind to be made. It was not possible at this stage to instruct bridge examiners in what they should look for when examining a bridge and when asking them to look for a fatigue crack. Perhaps Mr Berridge would like to explain his reference in this case.

98. The last sentence of $\S 38$ read as follows:

'But provided the parts of the bridge are accessible" for inspection and not shrouded or masked by concrete, for instance, detection of impending failure through corrosion fatigue is a simple matter.'

Mr Turton agreed with that, but it did not mean that no steel work should ever be encased in concrete or that concrete should never mask steel.

99. In $\$ 49$ there were these words:

'Before 1946 it was customary to ignore lateral forces other than those arising from wind or centrifugal action in the design of bridges on British Railways.'

Mr Turton's experience of another region--not the Western Region-was that these forces were taken into account when necessary. In most cases, the reconstructions on British Railways were comparatively small and it was not necessary to take them into account. But care was taken of them in the larger structures. He would not like it to be thought that these matters were completely ignored.

100. The main point of the Paper concerned the difficulty of trying to estimate the future life of bridges. It was necessary to get this matter into proper perspective. The Paper was concerned with existing bridges carrying railways. These consisted of a multitude of types and spans. They were constructed of various materials such as cast-iron, timber, brick, masonry, concrete and steel, and sometimes a combination of two or three of these materials in the same bridge. 
101. Some bridges carried fast main lines. Some were heavily used freight lines. Some carried both fast passenger and heavy goods traffic, and the density of traffic varied enormously over different lines. There were lines which conveyed little traffic at all of any kind. The age of railway bridges ranged from about 130 years to a few months, and by far the greater proportion of them were at the older end of the scale.

102. In their lifetime, very many of these bridges had seen many changes in the type of work which they had been called upon to do, from carrying something like the 'Rocket' with a few small coal wagons twice a day, to frequent fast express trains drawn by 100 -ton locomotives perhaps with heavy hammer blows. The life history in terms of live load application on any bridge was impossible to trace, nor did engineers know what the same bridge would be called upon to sustain in the future. This was not the same problem as arose when designing new bridges. In new bridges, engineers were concerned with ensuring that they would not fail in any circumstances which might prevail in the future, but with existing bridges the question was how long would they go on supporting loads of unknown magnitude and an unknown number of times, having regard to the unknown work of the past.

103. The only certainty was the traffic which was passing over a bridge at present. The rest was guesswork. What limits the life of a bridge, which was doing its job, was that it might deteriorate through lack of attention and eventually reach the point when it was left with insufficient material to support the loads imposed. There was a reference in the introduction of the Paper to Waddell's remarks, to which he subscribed, as he thought all engineers would.

104. If exceptional damage were discounted, it seemed that fatigue was the phenomenon which offered the most serious threat, and here there was some difficulty, for although much was known about the fatigue of specimens of various metals, little or nothing was known of fatigue life of built-up members. With this lack of knowledge, clearly it was impossible to predict the remaining life of an existing bridge. This applied equally, whether the bridge was in excellent condition or had suffered to the extent that something had to be done about it. If it were in need of attention, the problem was even more complicated since corrosion might or might not be accompanied by fatigue.

105. Because British Railways had so many old bridges which would have to go on performing their functions for many years, it was clearly of the utmost importance to know much more about the fatigue of those structures or at least of their several members. With this objective, British Railways' research department had constructed a large-scale dynamic testing plant at Derby which would shortly be in commission and where it would be possible to put full scale specimens on test.

106. It was hoped that the knowledge which would be derived from this work would be of great value, but even so, one side of the picture-past history-would remain in the dark. Nevertheless, when this knowledge was available, engineers would have one more important factor to add to those which the Author had described in the Paper and to assist them in arriving at decisions on whether to repair, strengthen or reconstruct. Those decisions would not be taken on these factors alone, for when all measurable factors had been taken into account, and one set against another and carefully weighed, the ultimate decision would depend upon experience and engineering judgment.

Mr A. H. Jenkins (British Railways, York) said that the Author had discusşed the problems which applied to all regions of British Railways, and it was therefore not surprising that he found himself largely in agreement with the Paper. But there were one or two comments which he wished to make to reflect experience on the NorthEastern Region.

108. The average age for all bridges removed or reconstructed for any reason whatever on the North-Eastern Region between 1952 and 1960 was 70 years for a metal bridge and 106 years for a masonry bridge. He was afraid that this was not 
strictly comparable with the figures quoted, because these had not been divided between wrought-iron and steel bridges. But he gave them as a matter of interest.

109. While the average life might be the proper figure to take for long-range planning, he made a plea for bridge lives to be considered in terms of a mortality table whereby a bridge of a certain age could be regarded as having a certain average expectation of life based upon past records.

110. He included here casualties from all causes, not just those due to deterioration of the material of which the bridge was made. Reconstruction due to corrosion on the North-East Region at any rate was not now the most common reason for reconstructing bridges. The reasons were almost invariably multiple. Obsolescence often played the biggest part. It was more often that the district engineer wanted a ballasted track for fast running and a local authority wanted a bridge widened and was willing to pay part of the cost. These were the kind of factors which governed the reconstruction of bridges and Fig. 2 seemed to express a truth long suspected at any rate by him-that it was rather difficult nowadays to justify the complete reconstruction of a bridge by physical deterioration alone-certainly in times of financial retrenchment.

111. As far as the investigations on the North-Eastern Region had gone, the present rate of mortality for masonry bridges had been fairly constant up to an age of 120 years, but for metal bridges it was fairly constant up to 80 years, and after 80 it doubled up to the age of 100 , and after that it trebled. Those figures were a little rough, but they indicated the general trends which should be taken into account, particularly with long-term planning. In 1960, the last year for which he had the figures, 1 in every 6 metal bridges on the North-Eastern region and 2 out of every 3 masonry bridges were over 80 years old.

112. He was glad that the Author had altered his figures of speed restriction costs, because Mr Jenkins had been expecting letters from various local authorities who had been charged the higher rates. He was delighted to see this put down in black and white so that it could be readily followed by engineers of all denominations and hoped that in future they would all become convinced that such costs represented a very real loss to the railways.

113. His impression was that at present fatigue was being over-emphasized. $\mathrm{He}$ was not sure that they had not been too premature in incorporating fatigue parameters in design methods to the extent which had been done. The only fatigue cracks which he had seen had taken a long time to grow and had been picked up in the normal course of inspection procedure. They had been so rare that they had been the subject of much discussion and argument. In his opinion brittle fracture was the danger.

114. In using Miner's law, were they not pretending to a knowledge which in fact they did not possess?

115. Examples of repairs were very interesting. Typical of the work going on all over the regions was the stressing of diagonals on St Julien's Bridge. There had been a similar example at Leeds in 1957. The work on the Royal Albert Bridge had reminded him of problems now awaiting him where they were investigating similar problems with a high-level bridge at Newcastle.

116. He had no further remarks to make other than that he regarded the Paper as one which every railway engineer ought to keep close at hand. He would certainly do so. He understood that an important part of their job as bridge engineers on the railways was to balance the risks of failure against the frequency of inspection. This was the point which should not be forgotten.

Mr L. E. Hawkins (London Transport Board) said that he was speaking about only one section of Mr Berridge's interesting Paper-speed restrictions; a section which might not be thought of very great interest, but which was an important matter. The 
business of a railway was to run trains and a railway engineer should be mainly concerned with facilitating the running and not restricting it.

118. Works by other parties frequently required railway speed restrictions and it was only fair that the costs should be charged to the parties concerned, but a true evaluation of those costs was not simple. There were a large number of factors.

119. Perhaps the greatest loss was in amenity, which could not be valued. Not everyone agreed with the poet that 'to travel hopefully is better than to arrive'. The engineer could only hope that the delayed passenger was compensated for his longer journey by the interest he could take in the work he could see from the train as he passed at a low speed.

120. The diagram in Fig. 1 showed on the left the time lost in travelling the restricted length plus the length of the train. It was correct for any kind of traffic, but the right-hand graph could be true only for a very limited range of conditions. Different locomotives and trains would have different braking and accelerating characteristics. Gradients adjoining the restriction would have an effect. Where, for instance, the restriction was at a bridge at the bottom of a dip, both the braking and acceleration times would be increased. If the restricted length were near any other restriction or station stop, the lost time would be decreased.

121. A permanent speed restriction could be allowed for in the time-table. The cost could then be made up from two parts, energy for acceleration, and a hire charge for train and crew for period of time lost. If the restriction were a temporary one, then the train crew should endeavour to recover the lost time on the remainder of the journey. On London Transport, the time-table allowed for a period of coasting between accelerating to a maximum speed from one station to the commencement of braking for the next station. The main cost of a speed restriction was in making up the time lost by running under power instead of coasting.

122. He was not clear how Mr Berridge had calculated the costs per hour for time lost. The acceleration cost was not proportional to the total time lost, as it was independent of the length of the restriction. He did not mention the cost of making up lost time by extra running under power.

123. Although he did not agree that a unit of cost per hour lost was a suitable measure of cost, he had, for comparative purposes, taken a typical London Transport service short speed restriction between stations and brought the cost to an hour-lost basis. This came to about $£ 21 / \mathrm{h}$ for a 6-car electric train for comparison with $\mathrm{Mr}$ Berridge's figure of $£ 3$ for a 6-car multiple unit diesel train. Mr Berridge had, of course, increased that figure in his introduction. He was interested, therefore, to know whether Mr Berridge could give a little more information as to how he had arrived at his figure and which factors had been taken into account.

124. As he frequently had to certify accounts for charges to other parties on account of engineering work including the cost of slowing down trains, he would not like it to be thought that Mr Berridge's figures were the last word on the subject.

Mr T. R. Gurney (British Welding Research Association) said that, although the Paper dealt largely with riveted structures, since welding had not been used extensively for bridge construction for very long, he wished to refer particularly to the problem as it affected welded bridges and especially to the problem of fatigue. He agreed with the Author that this was likely to be the main source of trouble in the future.

126. Before he did so, however, he wished to make a few general comments on the section of the Paper concerning fatigue. Referring to $\$ 35$, he felt that the second sentence could easily be misinterpreted and could be very dangerous, if taken out of context. It was impossible to visualize any bridge member without a stress concentration of some sort, since at least it must have connexions at its ends, and more usually it would have welded or riveted joints along its length as well. Hence a bridge member would normally have a fatigue strength well below the yield strength and the fatigue 'limit' would be the stress below which a crack could not propagate. 
127. Referring to $\$ 36$ he thought that the Author's concept of 'localized fatigue failure' could be very misleading, since small cracks could easily grow into bigger cracks. The crux of this problem was the reliance which could be put on finding small cracks during routine inspections and he would return to this point later.

128. Having been involved in the production of the revised fatigue rules for B.S. 153 he felt that he should point out that the permissible working stresses were not based on Miner's hypothesis. The basic permissible working stresses quoted in the revised clause of B.S.153 were produced by factoring laboratory constant amplitude fatigue test results, as explained at the Institution ${ }^{18}$ a few months earlier. Using these results one could apply Miner's hypothesis to determine fatigue life for a given stress spectrum. Also, the reason for quoting stresses instead of stress reduction factors had been that the fatigue strength of welded joints did not depend on the type of steel used, so that it was convenient to have one table for each particular joint. The alternative would have been a series of tables of stress reduction factors varying with both type of joint and type of steel.

129. Returning to the general theme of the Paper, Mr Gurney noted that the Author had stated that greater care would be necessary in design and fabrication, but he thought that more care would also have to be taken over inspection. He suspected that very few inspectors would know where to look for fatigue cracks and in any case finding them in their early stages would be very difficult. It was difficult enough in a laboratory when one knew where to look, but it must be infinitely more difficult in the field.

130. He asked whether, in the inspection of bridges, any attempt was made to find fatigue cracks and, if any were found, what was done about them. This was a most important question since there was certainly a tendency merely to weld up fatigue cracks and this was probably the worst thing that one could do. Such a repair could be guaranteed to fail again. He wished to draw attention to a Paper given by $\mathrm{Mr}$ Wise, of the British Railways Research Department, to the Institute of Welding about four years ago on the repair of fatigue failures. ${ }^{19}$ Although it referred particularly to rolling stock the principles applied equally to bridges. In general it was necessary to cut out the cracked area completely and insert a new piece. Whether or not one should use welding in such a repair would depend largely on the difficulties of site welding in any particular case.

131. Another problem with small fatigue cracks was the possibility that they might initiate brittle fractures. He had seen a large number of fatigue cracks, not in bridges, which had started brittle fractures. It was possible that in mild steel this might not be a danger but at the present time insufficient evidence existed and he thought that research on this problem was urgently required.

Mr E. E. Pool said that the Author had produced a very interesting Paper for bridge engineers, and if he made one or two petty comments, he was sure that the Author would enjoy the opportunity of making appropriate replies.

133. The Author had referred to fatigue. Dr J. A. L. Waddell, and Waddell was a bridge designer of note, had written in 1916- 'In properly designed structures the fatigue of metal is non-existent and there is no good reason for any longer considering that mythical bugbear'.

134. In $\S 35$, the Author seemed to subscribe to this view at least for main girders of simple spans. However, he corrected this impression in following paragraphs.

135. $\$ 38$ suggested that the presence of corrosion rust on a member could produce corrosion fatigue, but $\mathrm{Mr}$ Pool understood that repetition of stress in the presence of a corrosive fiuid was necessary to develop this phenomenon.

136. $\$ 40$ said that Miner's law, which presumably many bridge engineers a few years back might have associated with coal getting, was said to 'assume that the work done on the bridge to cause fatigue failure was equal to unity'. Mr Pool did 
not understand this, but the mathematical expression which followed seemed to be straightforward.

137. Dealing with the assessment of strengths of existing bridges, he said that in $\S \S 18-31$, the Author had described his methods for assessing the strength of existing bridges. Impact allowances and permissible stresses were adopted which varied from those given in B.S.153 Girder Bridges. Could the Author say whether similar relaxations were applied to the strengthening schemes and reconstructions. If so, would he consider that the time was ripe when B.S.153 might usefully be amended.

138. Dealing with the suggestion that the compression flange failed first, he assumed that in $\$ 33$, the reference was only to solid web girders. Even so, it appeared unwise to assume that in all cases buckling of the compression flange would give the first sign of failure.

139. Sway bracings were referred to in $\S 51$ as necessary adjuncts to bracing systems. The Author knew that the Indian steel bridge code gave rules for their design, but in B.S.153 their use was at the discretion of the engineer. Would the Author give his views?

140. Among the very interesting examples given in the Paper, the Kotri Bridge, taken from Mr Berridge's Indian experience, had been dealt with by the firm which Mr Pool served. Designed in 1900, it had been strengthened by doubling the main girders in 1930 so that the existing main girders could work to permissible stresses under the new heavier standard loading and cantilevered roadways. This had been a clear-cut case which had not needed the application of the economic investigations given in the Paper. The existing steel work had been in first-class condition and had been re-used to its full capacity.

141. The figures for the cost of speed restrictions for the Chepstow Bridge were particularly illuminating, but he asked the Author whether cases arose in which it was considered better to suffer speed restriction than to strengthen or reconstruct. His examples all compared repairing costs with reconstruction costs.

Dr T. P. O'Sullivan (T. P. O'Sullivan \& Partners) wished to emphasize that the Paper was a milestone to an extent which was not entirely obvious. It would be very valuable to those building any type of bridge for any purpose, whether pedestrian, road vehicle or waterway bridges, or even any type of suspended structure. Admittedly, certain of the particular items applied specially to railway work, but the Paper was worthy of a much more extensive audience.

143. He wished to make one point in connexion with whether a bridge should be reconstructed or strengthened. He quoted from a Paper which he had presented in the Proceedings. ${ }^{20}$ In it he had said that in providing a steel framework for the purpose of supporting structures of magnitude such as bridges or large works of an industrial nature, the engineer was often confronted with the task of choosing between two courses of action. On the one hand, it might be considered politic to make provision for future development or change of use entailing allowances for loading over and above that specified at the time the work was begun. By so doing, however, heavy expenditure might be incurred which might never be justified. On the other hand, if provision for additional loading were not made, but were subsequently required, the engineer might at a later date be confronted with a technical problem of some considerable difficulty. Whichever course be adopted, he was open to criticism either for being responsible for what might be considered an extravagant design or, alternatively, for showing lack of foresight.

144. Dealing with the problem of strengthening bridges, he wished to indicate briefly a problem which had given rise to his Paper. In the late 1940s work had been carried out on a structure which consisted of a roof of $330 \mathrm{ft}$ span at Bristol built for the Brabazon assembly building. It was 8 acres in extent and was now being used for the supersonic aircraft under construction.

145. The problem arose that after this structure was built it was desired to extend 
the canopy, and the question was, what should be done? Could this canopy be extended (Fig. 31)?

146. The structure was two pinned at the base and there was a tie at eaves level. As it was doubly redundant it was impracticable to produce an entirely economic design. Under the new conditions, certain of the truss members would be overstressed. Was it necessary either to release the load from the complete arch by jacking at the centre, or from the over-stressed members individually by local jacking, in order that these members could be replaced by stronger sections? Both these solutions presented difficulties. The solution finally adopted was to strengthen the members under load, by adding additional unstressed material. Fig. 31 shows in heavy lines the members requiring to be strengthened.

147. Consider a tie of cross-section 1 sq. in. under a load $T$, being the working load, with corresponding extension $X$. It was assumed that $2 T$ was the elastic limit, with corresponding extension $2 X$ and that the member would fail for its purpose at this load. It was now assumed that with the tie under force $T$ a further 1 sq. in. of unstressed material was added to it (Fig. 32).

148. Then the addition of a force $2 T$ (giving a total force of $3 T$ ) would have caused an additional extension $X$, bringing the parent metal to yield stress and the added metal to working stress. Further addition of load would still have been possible as the parent metal would have yielded while the added metal continued to accept additional load, until at a total load of $4 T$ and extension of $3 X$ the added material would have reached yield stress.

149. It was thought that because of the importance of the matter there should be some experimental evidence to substantiate this theory. Tests on both tension and compression members were carried out in Dorman Long's machine at Middlesborough which took loads up to 1200 tons, and results were found to be satisfactory. The structure was strengthened on that basis without any release of stress for the additional load. Would the Author say whether this might not help the economics of new structures and strengthening? He might like to turn over the pages of the Paper which Dr O'Sullivan had quoted.

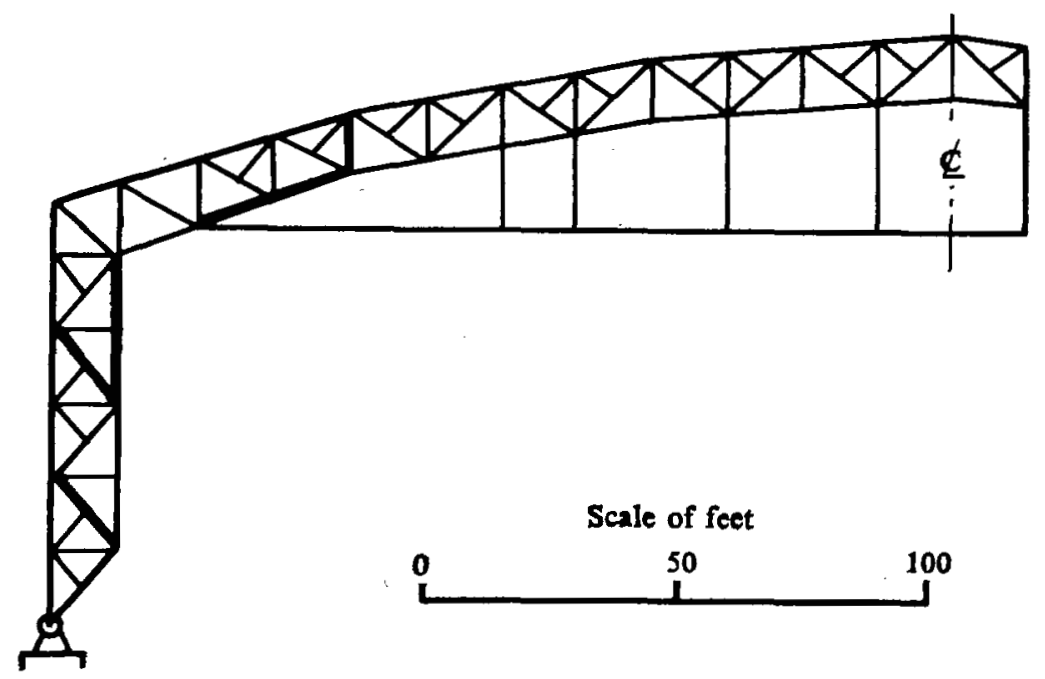

Fig. 31: Elevation of half Main frame of a RoOF 


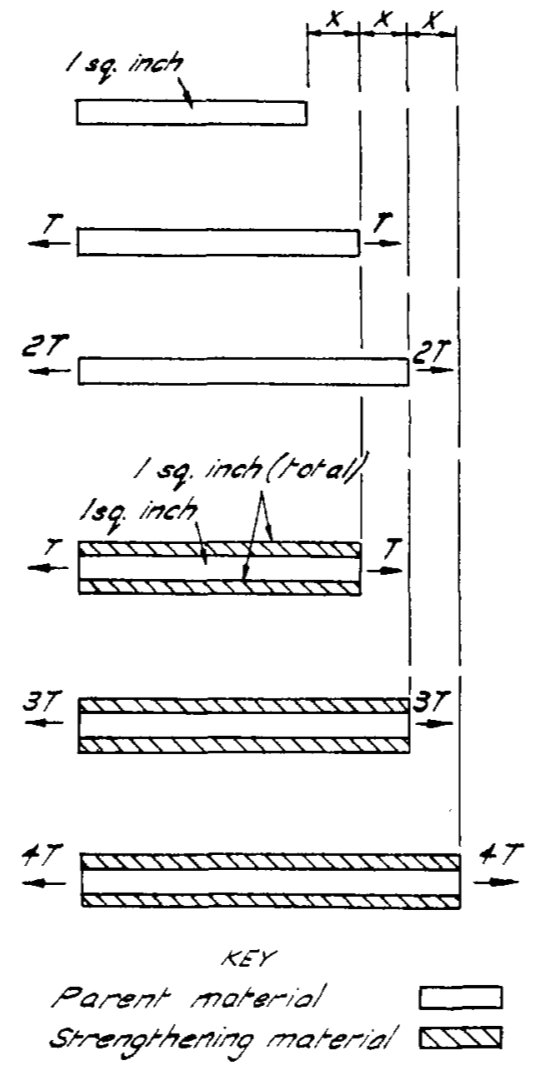

Fig. 32

Mr J. K. Bucknall (Southern Region, British Railways) said that the Author had asked why railways all over the world were plagued with recurring expenditure on existing bridges. He suggested that in the most frequently occurring type of railway under-bridge-the half-through type riveted plate girder up to $100 \mathrm{ft} 0 \mathrm{in}$. spanthe main reason for heavy expenditure was ccrrosion of parts inaccessible for maintenance and often badly drained. This had been aggravated in many cases by neglect, partly as a result of two world wars. There had also been a tendency to concentrate on the worst bridges, thus allowing the better bridges also to get in poor condition.

151. The Author mentioned 'future requirements of the Railways'. Would he clarify this? Did he expect a change in design loading of bridges or merely that a particular bridge might not be required in a future railway system? Renewal of 
existing bridges had never been contemplated when they were designed, and renewal or part-renewal of large, complicated structures was likely to cause so much interruption to train services that sometimes uneconomical repairs had to be undertaken.

152. When considering repairs or renewal, it was very important that the full extent of any such repair be accurately assessed. Hidden defects in old bridges could necessitate expensive extras, thus increasing the cost of repairs almost to the figure required to renew the structure. A further point was that future maintenance of new structures should be very much lower than that of repaired or strengthened existing structures.

153. On the Southern Region there was a lack of detailed knowledge of the strength of existing bridges, and in 1946 a survey had commenced and this had provided information about the capacity of every existing under-bridge. Following routine examination, it was a simple matter to reassess a bridge which had suffered loss of section.

154. The Author stated that fatigue failure would not occur in main girders provided that the stresses were not alternating. This statement was true only if certain types of welding detail were avoided, and in fact in nearly every case fatigue was taken into consideration when designing main girders to B.S.153.

155. The Author mentioned possible fatigue failures in deck systems, but particularly in modern standards, concrete encased decks were very common in railway bridges, and where there was such encasing it appeared to preclude all chance of detection of fatigue cracks at positions where they were most likely to occur. Would the Author comment on this? It would also be interesting to know whether fatigue cracks in the early stages were detectable through two or three layers of paint. How could they be seen in those circumstances?

Mr J. C. Lucas (British Railways Research Department) said that the statement in $\$ 35$, with regard to the fact that the loading necessary to cause fatigue failure of a principal member of a structure would be greater than those causing permanent distortion under straightforward loading was true only for plain, polished plate specimens. As soon as riveted holes, surface defects, etc. were present, the load range equivalent to the endurance limit of the girder could certainly be less than that which would produce significant permanent distortion due to yield.

157. In $\$ \$ 43-46$, the Author had dealt with the prediction of the future life of a bridge. He had referred to the bridge at Sharpness. Mr Lucas would deal with the assumptions which entered such a prediction, and this would give an idea of the value which would be placed on it. Personally, he thought that it amounted to rather an inspired guess.

158. First, in this case the bridge was highly redundant. This meant that if the prediction was far from a reality, the failure of one member of the double system of diagonals would not be catastrophic. Failure of one of the members would not be likely to affect the safety of the bridge. Secondly, it was assumed that the previous frequency and type of live loading was the same as that observed during the perod of the test. Thirdly, it was assumed that the fatigue endurance of the wrought iron in this bridge was the same as that determined from specimens from other bridges of a similar age. Fourthly, it was assumed that the stresses were measured at the positions of maximum stress in the bridge components. Fifthly, it was assumed that Miner's hypothesis was applicable for the components of this bridge and that there was only one load cycle per train. Finally, the fatigue endurance was based on a probability that 1 -in-100 of these would fail. His personal opinion was that the figure of 14 years was no better than an inspired guess, and if he were asked to apply limits to this figure he would put them at minus 10 years and plus 100 years. This was not intended to decry the estimate given. In the case mentioned, it had been necessary for some action to be taken, but it should be borne in mind that this 14 years' period was not an absolute value but was a guide. 
159. He asked if he might give a little more information on the method by which the impact factors given in $\$ \$ 22-24$ had been obtained. A number of bridges (ten) had been selected as being representative of a fairly common type of existing bridges on British Railways. No unusual bridges had been used. These had all been on lines which were under fairly heavy mainline traffic, and the traffic had ranged from steam to diesel and electric traction. Electrical resistance strain gauges had been attached to the main structural components of these bridges, notably on the main girders, cross girders, and rail bearers. It had been a case of recording one train and, if necessary, resetting afterwards. Up to 1000 trains had been recorded as they passed over each of these bridges and stresses had been measured from 12 gauge positions. The gauges had been put usually at the centre span but also away from the points of stress concentration. The maximum stress per train had been derived from these records, and these had then been segregated into particular classes of locomotive. Therefore, for any one gauge position on a member, it had been possible to obtain the incidence of various stress levels of any one particular type of train. This had been done for a total of 10 bridges ranging up to a maximum main girder span of $81 \mathrm{ft}$.

160. By virtue of the segregation into classes of locomotive, it had been possible to compare the equivalent stresses calculated on a static basis for each of these classes of locomotive with some statistically derived function of the measured stress levels. In other words, it had been possible to make a comparison with stresses calculated by normal drawing office means.

161. It had been found that the mean stress for any one particular type of locomotive and the static calculated stress based on the normal simplified assumptions of assessment showed good agreement, and that 1.3 times the static calculated value agreed very well with the stress at the mean plus three times the standard deviation. This was the 1-in-1000 probability to which the Author referred.

162. There was much more to it than this, but this was the reasoning behind the derivation of these factors.

Mr S. Turley (Freeman, Fox \& Partners) said that he was not clear whether the impact factor of 1.3 included lurching effects. He assumed that the lurching was not included in this factor because it varied with the distance apart of the girders, but on the other hand it was difficult to see how it could have been eliminated from the statistical analysis of recorded stresses. It was welcome to see the rather cumbersome Foxley-Greet formulae in B.S.153 being replaced by the simple factor of 1.3, even though most speakers in the discussion had wondered whether the simplification had gone too far.

164. Turning to permissible stresses, he said that he had reçently been concerned with the checking of steel bridges on railway lines in Africa. It had been decided to use the same permissible stresses for mild steel as those given by the Author in Table 2. Incidentally, tensile tests had been carried out on samples of steel from some of the older bridges dating from 1905, and in all cases the minimum yield had been in the region of 16 tons/sq. in.

165. The investigation of this railway involved 147 steel bridges constructed between 1905 and 1934 . This had revealed the same lack of adequate lateral bracing as that mentioned by the Author in $\S 47$. Out of 114 deck type bridges, all with sleepers carried directly on the top flange of main girders, 77 had no lateral bracing whatsoever, 24 had an inadequate bracing system, and only 13 could be considered as satisfactorily braced. None of the 33 through-type bridges on the line had lateral stringer bracing systems, although three which carried road as well as rail traffic were satisfactorily braced on account of the troughing and concrete deck.

166. These bridges had been taking traffic satisfactorily for up to 50 or 60 years. If they were analysed, assuming no lateral system whatever, with the normal nosing 
loads and lateral wind loads, they were hopelessly over-stressed. One could only assume that, since racking forces such as nosing and wind load on trains could not be acting without a corresponding large vertical load, some sort of Vierendeel truss system consisting of sleepers and top flanges of stringers was formed, the necessary corner moments being taken in friction.

167. This was a problem which was recognized in other countries. For example, the Indian bridge code had a clause which read:

'Existing deck type plate girder spans with transverse sleepers need not be condemned on account of the absence of lateral bracings, provided they show no signs of distress or undue lateral oscillations.'

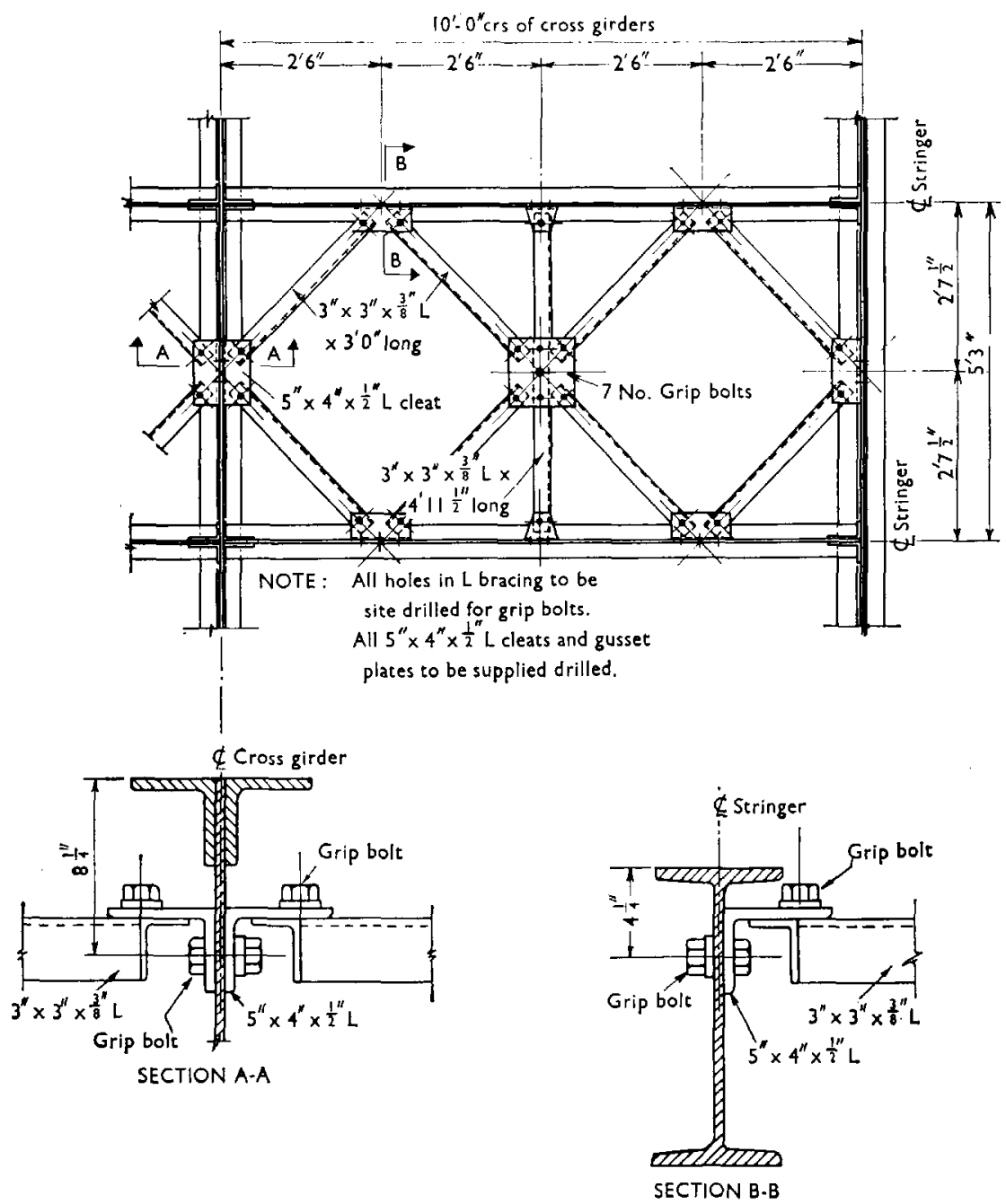

Fig. 33: Plan of typical STRINGer BRacing 
168. Present policy on this African railway was not to add lateral bracing unless a particular bridge required other strengthening either for present or for assumed future loading. It was a fairly simple matter to add lateral bracing without interfering with rail traffic. One method which had been used on this railway was shown in Fig. 33. As on all bridges in this line, the sleepers were carried directly on the top flange of the stringers, so that the bracing system was located just clear of the underside of the sleepers. The cleats were sent out already drilled, and the members themselves were drilled to suit at site, the connexions being all made with waisted grip bolts.

169. Finally, referring to fatigue, he thought that he was tight in saying that Miner's rule did not necessarily say that $\sum(n / N)$ equals unity. In fact, it could vary from 0.8 to 3 , and the figure of not greater than 1 given in B.S.153 was fairly conservative.

Mr Webb (Braithwaites) reinforced the point made by Mr Pool. Many speakers had questioned the extent of impact factors in fatigue, but an ounce of practice was worth a ton of fatigue, and there was no doubt that the Author was a master of the practice.

171. British Railways had found that 1.3 as the impact factor was quite sufficient with 12 tons stress in mild steel. Obviously, Victoria Street were being left behind. He hoped that they would follow the magnificent lead given by the Author and British Railways.

The following contributions were received in writing:

Mr M. Sas-Skowronski (East African Railways and Harbours) wrote that the Paper was a valuable contribution to the knowledge on railway girder bridges and was of particular importance because it focused attention on other properties besides strength.

173. There was some evidence that where there was no ballast and the bridge member concerned was directly below the running rail, ratio of recorded stress at speed to the static live load stress would equal or exceed 1.65. The Author's value of 1.5 , based on Pencoyd and Indian formula, was rather optimistic and should not be taken into account in such countries where the maintenance of permanent way bridges or rolling stock was of low standard.

174. Where, caused by open joints or rough or flat wheels, the impact was more or less in the nature of a 'blow' upon the structure, the other factors such as unbalanced locomotive driving wheels, rough or uneven track, eccentric wheels, rapidity of application of load, deflexion of beams, which gave rise to variations in the action of the vertical load, amounted in effect to varying a load or a series of impulses. In either case the result was to produce deflexions and stresses in excess of the static values.

175. In the design of bridges, the impact stress was provided for either by increasing the live-load stress in accordance with some empirical rule supposed to represent the impact, or by a reduction in the live load working stress, below what would be used in case the stress were wholly static.

176. A great variety of impact formulae had been used, most of which expressed the impact ratio or percentage in terms of span length. The maximum impact percentages as determined by tests was given by the formula.

where

$$
I=\frac{100}{1+\frac{L^{2}}{20000}}
$$


177. The experiments obtained in the series of tests indicated that the ratio of dead load to the live load was a very important factor together with the series of impulses to set the structure into vibration.

178. In the case of short span bridges, supported on solid concrete abutments or piers, with adequate provision for expansion or contraction, these impulses would be repeated only two or three times and would disappear very quickly, but in the case of long span bridges, they would be repeated many times. If these impulses corresponded in period with the normal rate of vibration of the loaded structure, the effect would be cumulative and the vibration would be greatly increased.

179. Such cumulative effect could not occur for bridges of very short span length, as the normal rate of vibration of such a bridge was higher than the rate of rotation of the driving wheels at the practicable speed.

180. During the passage of a train, the total weight on the bridge varied to a considerable extent. The normal rate of vibration of the structure also varied. The speed at which the impulses considered showed a cumulative effect might be termed as the critical speed.

181. The results of the tests showed clearly the importance of critical speed, and the maximum vibrations were found to occur generally through a narrow range of speed corresponding to critical speed. A speed in excess as well as below the critical speed, would cause vibration of less amplitude than those caused at or near the critical speed.

182. For short span, such that the critical speed was not reached by the moving train, the impact percentage tended to be constant so far as the effect of the counterbalance was concerned, but the effect of rough track and wheels became of greater importance for such spans.

183. It was a well known fact that when the compressive force in the structural element increased, the vibration of the element decreased, but with the increased tensile force the vibration increased proportionally.

184. Mr Sas-Skowronski had analysed an existing steel viaduct consisting of $20 \mathrm{ft}$ and $40 \mathrm{ft}$ spans, supported on steel trestles $72 \mathrm{ft}$ high. The girders of this viaduct were designed as simply supported beams, but in practice they were restrained transversely, allowing at one end for free longitudinal movement only over its bed plate. Due to friction between the bearing plate of the girder and bed plate, some kind of continuity was achieved, and the vibration from one span could be transferred to the adjacent one through the steel trestle and common bed plate. This viaduct was designed and constructed in 1901.

185. The ratio of bending moment due to live load to the bending moment due to dead load was $8 \cdot 20$, the depth of the $40 \mathrm{ft}$ span girder $3 \mathrm{ft} 0 \mathrm{in}$. only, the width of top and bottom flanges $12 \mathrm{in}$. only. The theoretical calculated stresses due to dead end and live load were:

$$
\begin{aligned}
\text { tensile stress } & =7.17 \text { tons/sq. in. } \\
\text { compression stress } & =7.40 \text { tons/sq. in. } \\
\text { maximum theoretical deflexion } & =0.71 \text { in, but recorded } 1.75 \text { in. }
\end{aligned}
$$

186. The excessive amount of loose rivets ( $86 \mathrm{No}$. in one span) and broken welds between the rail bearers and the main girder had indicated overstraining and very laborious analysis was carried out. In over 200 spans of viaducts, between 61 to 121 loose rivets in one span were found; but where the similar $40 \mathrm{ft}$ steel girder was supported on the concrete abutments and piers, but not on the high steel trestles, a negligible amount of loose rivets was recorded (below 6 in one span).

187. Mr Sas-Skowronski came to the conclusion that vibration of viaducts was excessive, not only due to vertical loading of the passing train, but also due to wind pressure on trestles and girders. Influence of excessive cant and centrifugal force was also taken into account and it was found that it was rather difficult to trace it from a theoretical point of view, but experimental determination was the only practical method of determining the results produced. 
Mr T. Baldwin (British Railways Research Department) wrote saying that he found the Paper of great interest, and not least that portion of it dealing with the economics of repair and reconstruction. In $\S 10$, the Author mentioned that it was "prudent to set aside additional sums to assist in meeting the increased cost of replacement caused by inflation'. This would seem to be a very wise measure, but he could not see where it had been carried out in the examples quoted. It mystified him because the Author was clearly very much aware of the point and used Example 2 to show that a cost of $£ 400$ in 1902 became $£ 4100$ in 1962 , due to inflation. This increase of 10.25 times in 60 years agrees well with a figure of $4 \%$ per annum, i.e. $2 \cdot 2$ times in 20 years, or 10.5 times in 60 years, which is sometimes assumed. Presumably, due consideration was given to this factor, and it would be interesting if the Author could outline the method he used. The relatively high interest rate of $6 \%$ was presumably associated with inflation, and reduced the initial sum to be invested, so that it was all the more important to take into account the inflated sum that would be finally required for reconstruction. Incidentally, it would seem that the sums laid aside for bridge reconstruction at 60 year intervals to infinity should be a very attractive feature of branch line closures.

189. The references to corrosion fatigue were of great interest, in relation to the life of bridges in this country, and one cannot help contrasting the lack of knowledge of safe life under corrosive conditions with the detailed requirements of B.S.153 in the application of Miner's hypothesis. For example, one wonders how much an estimate of endurance under combined corrosive attack and continuous sine-wave fluctuations of stress should be modified because the stress fluctuations due to traffic were in bursts, due to the successive wheels and vehicles in a train, followed by fairly long static periods between trains.

190. The need in this country to make the parts of bridges below deck level readily available for close and frequent inspection was a prime one, as the Author pointed out $(\$ 38)$. Where coal or other corrosive traffic was carried, only local failures in the water-tightness of the deck became major factors influencing the life of the bridge, and early inspections and appropriate action must result in handsome economies in the later years of the life of steel bridges. The examples of common faults and remedies given in the Paper were of great value.

Mr B. Bramall (British Railways Research Department) wrote that at the close of discussion, Mr Turley had referred to bridges without sway bracing.

192. The Vierendeel effect was manifest in certain bridges of the Ceylon Government Railway. ${ }^{21}$ Horizontal loading was severe due to centrifugal forces on sharp curves. It could be estimated fairly reliably, and, of course, could be varied by running at differing speeds.

193. An attempt was made to evaluate the proportion which was resisted by individual flexure of main trusses in the lateral direction, and that taken by Vierendeel action. The evidence suggested that under trivial loading the load was sustained by individual bending, but as it increased combined action as a horizontal truss developed. The bridges were open deck type with cross girders at four foot intervals, and it would appear that the combined action developed as their connexions took up small limits of play.

194. Horizontal diagonal bracing was added to all such bridges later, and a comparative test confirmed its desirability.

Mr T. Henry Turner wrote that in this instructive Paper the Author asked why, if what Waddell wrote in 1921 was true, railways all over the world were still plagued with recurring expenditure on their bridges. Some helpful answers to that question might be indicated if one first asked what Waddell had in mind for 'a metal bridge'. Bridges in service were made from a variety of wrought irons, cast irons, mild steels, copper-bearing steels, low-alloy steels, and even aluminium alloys. 
196. Waddell's ideas of scientific design and honest careful building had hardly included modern grit-blasting, galvanizing, metal spraying, corrosion inhibition at later inaccessible surfaces; also streamlining by grinding off sharp corner metal apices, and puttying up all overlap joint concavities that trap rainwater and condensation, as shown in Fig. 34.

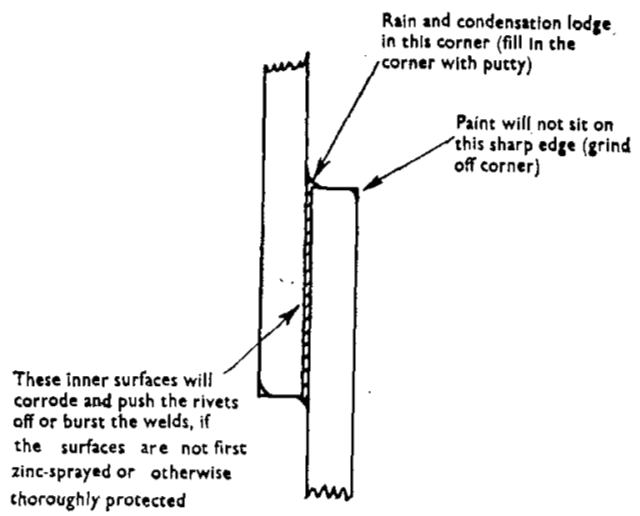

FIG. 34

197. By referring to corrosion several times in this Paper the Author showed his awareness of these aspects of bridge design and maintenance. But a metallurgist, chemist or corrosionist would underline in red all such references, because a properly designed and effectively surface-protected steel bridge would never fail.

198. It was especially important to note that the corrosion of bridges was never a uniform reduction of section, such that one might easily measure a square inch as required to use the tons/sq. in. figures given in Table 2. Mr Turner recalled, for example, an L.N.E.R. bridge that he had to inspect because it was in some parts very seriously corroded away as a result of acid fumes from a nearby glass works. The corrosive atmospheric moisture had lodged on the top of many members where they crossed other diagonal members, and the corrosion had incised a local gooving almost as serious as a saw cut, right across the tension members.

199. Where the Author dealt with 'Modes of failure' in $\$ \$ 32-39$, he recalled a somewhat unusual confirmation of his statement that the yield strength of iron would not have changed during the lifetime of the bridge. Forty years ago he had examined a Roman nail under the microscope and found that after some 1500 years, the grains under the head were not equiaxed, which indicated that the work hardening effect had not been eliminated. In the absence of accidental fire or other local heating to a red heat, any local strain hardening would remain and help to maintain the strength of the bridge.

200. The Author stated, in $\S 34$, that a steel bridge could fail by reason of fatigue, but he was convinced that pure fatigue failure must be almost unknown in bridges whereas corrosion fatigue was common. This was not a quibble, but an essential distinction that could be of great help to civil engineers. Corrosion fatigue would never occur unless the protective coating of the steel had first failed locally; thus permitting corrosion to accelerate the growth of minute metal surface irregularities into dangerous fissures.

201. To prevent the corrosion fatigue of a steel bridge it was therefore more important to study the permeability, softening or embrittlement, plasticity or 
powdering, of the protective coating, than to study the fatigue of steel in the dry air of laboratories. Primarily, one must study the action of sunlight, rain, condensation, wind, snow, hail, and frost on the coating; and note especially its coefficient of expansion and its behaviour on warming and cooling adjacent to the steel, which had not the same diurnal expansion and contraction.

202. Railway bridges were plagued by recurring expenditure because of the failure of their surface protection. The future life of steel bridges depended upon preventing the failure of the protective coatings. To prolong the effective life of protective coatings on bridges, and therefore of the bridges themselves, what should an engineer do and what should he not do? The answers to those important questions would be indicated if one were to list what must be done in order to eliminate a protective coating from the surface of steel. One would probably hammer it, scrape, chip, burn it off, soften it with spirit solvent or alkali, if a paint; etch it away with acid if zinc; abrade with sharp grit, and blow away or shake off the detritus.

203. It was known that the wear of steel railway lines was due to the rubbing, blowing, washing, or shaking away of rust; the wearing away of railway steel bridge components is similarly often due to the shaking away of steel that had first been converted to rust.

204. How did one test the ability of a surface coating to resist disintegration by vibration? Sunlight burnt it, rain washed it, winds winnowed away the rust after vibration had disintegrated the corrosion product. Paint testing establishments did not seem to have included this feature in their work but it was present in all bridges.

205. What caused the most vibration, rattling, shaking, of a railway bridge? If a bridge failed through the shaking away of products of corrosion this was a vitally important question. Somewhere, therefore, in the Author's argument, one should focus on the running rails that were the raison d'etre of the bridge, its track.

206. Rail joints caused hundred of tons of vehicles, passengers, and freight to dither about and of course simultaneously cause vibration of the bridge that accelerated the failure of its essential protective coatings. Many steel railway bridges would be helped if they were now fitted with long flash-butt welded lengths of rails in place of mere $60 \mathrm{ft}$ lengths. Replacing bridge rails with jointless or at least longer flash-butt welded lengths offered a way of reducing the repeated stresses on the bridge and of minimizing the loss of steel due to vibrating away corrosion, erosion, and abrasion products from steel, paint or zinc.

207. The older constructional steels had a good damping capacity. Vibration and corrosion fatigue was more to be feared where mathematically minded engineers had reduced weights, and higher tensile strength steels had permitted the relative increase in surface area exposed to corrosion per ton of steel employed.

208. The use of white or light coloured paints, especially in the more inaccessible parts would clearly indicate cracks, rubbing places where movement took place, and rust staining and so point to failure of the bridge's protective coating.

209. The more zinc one could get on the surface of a bridge, the better, because a failing zinc coating could not accelerate the corrosion of steel, whereas a failing coat of paint might do so. For the longest service life in a steel railway bridge, jointless track rails were a sine qua non.

The Author, in reply, referred to $\S 7$ of the Paper and gave the following revised hourly costs for restrictions in 1962:-

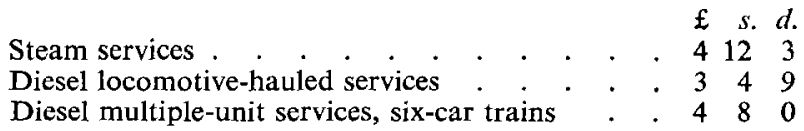

211. He thanked Mr Barnwell for introducing the Western Region underbridge programme, Fig. 23, and said that 3525 bridges in a route mileage of 3451 were alleged to cost, track excluded, about $£ 450$ per route mile year. Reference to the 
repairs and strengthening of the viaducts in Cornwall had demonstrated how heavy expenditure was saved through planning on proper engineering lines. He drew attention to Asoka's pillar in Delhi as being an example of wrought iron, continuously protected from corrosion through the suitability of its environment, still in its as-made condition after exposure for 1600 years. He further quoted the results of fatigue tests on samples of wrought iron 110 years old taken from Brunel's 300-ft spans in the Wye river bridge at Chepstow. Some samples had been subjected to more than two million cycles of loading during their life in the bridge and stressed unidirectionally in the range from 2.9 to 4.4 ton/sq. in. in tension. Some had carried no load at all, and some had been subjected to alternating load cycles with the stress ranging from 1.0 ton/sq. in. in tension to $3.61 \mathrm{ton} / \mathrm{sq}$. in. in compression. The results of these tests had shown: "There is no significant variation in the remaining fatigue life of the wrought iron due to its previous condition of loading.'

212. Mr Henry Turner $(\$ 199)$ seemed to agree. So, the Author concluded, it was reasonable to assume that wrought iron and mild steel, not corroded and not stressed beyond the yield point, remained unchanged. Therefore, with regular maintenance and especially prompt attention to repainting wherever and whenever protective coatings showed signs of breaking down, girder bridges could be made to last much longer than they had in the past, and it was possible to spread the 1980 hump without either curtailing line capacity requirements or incurring uneconomical expenditure. It was a matter for careful planning and stubborn resistance to neglect because with modern techniques, especially strengthening by prestressing, high strength friction-grip bolting, etc. (not site welding, be it noted) the usefulness of girder bridges could be prolonged almost indefinitely.

213. The Author had been associated with $\mathrm{Mr}$ Gelson during the investigations into the effect of impact on girder bridges in India and he was grateful to him for his valuable contribution. He agreed that the excessive batter on rail ends seen on some B.R. track appeared to show a weakness in the fish-plated joints $(\S 75)$, but the increasing use of the welded joint should soon remove the worst of the track effects from bridges. There were so many uncertainties over maladjusted wheel loads, sprung and unsprung weights, springs locked and unlocked, etc. in the live load, to say nothing of variations in load distribution and track relief, and the differences between design assumptions on the drawing board and the treatment of the steel during fabrication in the shops, that he welcomed the simplicity of the 1.3 factor applied to the live load for spans up to $80 \mathrm{ft}$ in length. The factor resulted from statistics based on actual measurement. Mr Lucas had answered the questions in $\S 84$. The intermediate or design inaccuracy factors in Table 1 were estimations, whereas the impact factors given in that Table were founded on recorded fact, and it seemed probable that in estimating the former, a rounding off of the resulting factor had some influence. Referring to $\S 93$, the lateral loads had been recorded on straight ballasted track without reference to the presence of bridges.

214. Referring to Mr Turton's remarks (\$96), there was ample evidence at Paddington that the 'enhanced' permissible stresses had not been in vogue on the G.W.R. prior to 1947. For his reply to $\$ 97$, the Author referred Mr Turton to the examples he had given in $\$ 71$ and 72 of the Discussion on reference 18 (Proc. Instn civ. Engrs, vol. 27, February 1964, pp. 399-400).

215. He agreed with Mr Jenkins $(\$ 113)$ that fatigue failure was an unrealistic bogey. He thought it stemmed from a lack of proper understanding of locked-up stresses in girderwork fabricated by welding. He had yet to come across an example of fatigue failure in a girder no matter whether it had been riveted or welded; though examples of corrosion fatigue, attributable to neglect or inaccessibility, and concentrations of stress leading to stressing of the fibres beyond the yield point, generally due to faulty design, were legion.

216. The Author thanked Mr Hawkins for enlarging on the cost of speed restrictions. The charges on lines worked by electric traction were likely to be more 
reliable than those used by steam and diesel-hauled stock. There were many more imponderables in the latter, and the annoyance to the travelling public was likely to be much more in evidence.

217. The Author had a special word of thanks for Mr Gurney because the British Welding Research Association had been largely responsible for the revised fatigue clause for B.S.153.18 Referring to $\S 126$, he had intended the working stresses in $\S 35$ to include the maximum stress at concentrations of stress at connexions.

218. Regarding modes of failure, discussion had centred on fatigue $(\$ \S 126,154$, and 156), and brittle fracture ( $\$ 113$ ). His knowledge of localized fatigue failure had been solely at points of high stress concentration such as occurred at re-entrant angles and similar features of bad design. During more than forty years, he had never succeeded in finding any reliable evidence of pure fatigue failure in plate girders and truss girders in railway and highway bridges (Discussion on reference 18.) Examples of corrosion fatigue had been common; but loading conditions in girder bridges were not conducive to failure through pure fatigue and it was wrong to draw comparisons with failures from that cause in parts of rolling stock. Past experience of riveted trusses had shown that the worst that had seemed likely to happen at the ends of bridge members had been a loosening of rivets when they had been overstressed in bearing; and he certainly did not share Mr Gurney's apprehension ( $\$ 126)$ about such members when the connexions were secured with properly tightened high strength friction-grip bolts.

219. It was really only since fabrication by welding had come into fashion that the propagation of cracks through brittle fracture had come to be considered in bridge girders. But this did not constitute a risk where the steel used was of the correct notch ductile quality having the minimum Charpy impact test value at the appropriate low temperature. There would be no sense in building bridges calling for close inspection for the detection of minute cracks. There was neither the time nor the qualified examiners for such a task.

220. Deterioration through rusting, and corrosion-fatigue were the real enemies; the time to guard against their attack was when the first signs of breakdown showed in the protective coating. The Author agreed with Mr Henry Turner $(\$ 200)$ that excessive vibration, the result perhaps of a 'badly working' bearing, was apt to disturb paintwork.

221. Dr O’Sullivan appeared to have $\S 56$ in mind when he put forward his ideas on strengthening a bridge member, overstressed under live load, by adding more steel without relieving the existing steel of its dead load stress ( $\$ 142)$. Attractive as the scheme had seemed, it would not do for a girder subjected to dynamic loading. The deliberate overstressing of the original section would raise the yield point, but the elastic limit and the range of proportionality between stress and strain would be reduced. Strain in the section overstrained would develop by 'creeping'. Such hysteresis within the limits of elasticity could bring about ultimate failure under repeated applications of stress much below the ultimate static strength - fatigue failure, in fact-the resistance to the repeated stress depending upon the frequency of application of stress.

222. The Author had difficulty in believing Mr Sas-Skowronski's reference to what seemed to be a very excessive recorded deflexion ( $\$ 185)$. A measured deflexion of $1.75 \mathrm{in}$. at the centre of a $36-\mathrm{in}$. deep steel plate girder in a $40-\mathrm{ft}$ span, stressed within reasonable limits, appeared to indicate some error. The ratio of deflexion to length of span came to 1/274. Brunel had quoted a rule whereby the deflexion of a wrought iron girder railway bridge should not exceed 1/40 in. per foot length of span. ${ }^{5}$ Although the Author had come across deflexion as high as 1/360 of the span, he considered $1 / 480$ to be on the high side for bridges on fast running lines.

223. Mr Baldwin had drawn attention in $\$ 189$ to the departure from Miner's hypothesis due to the inevitable effects of protracted 'rest' periods between trains; and the Author agreed with Mr Jenkins (\$114). No doubt Miner's law had seemed 
a way to forecast the life remaining in a bridge, but he would be the first to agree that the answer would lie within very wide limits.

224. Replying to $\S 188$, the Author explained that the cost of supplying and erecting the 1902 superstructure of the Little Somerford bridge in 1962, Example 2, had been based on a scale similar to the Hollyer-Hill scale used in the building industry, but dealing with the cost of supplying and erecting the iron or steel superstructures of plate girder railway bridges. The factors used in this scale between 1880 and 1963 had been plotted in Fig. 35. The figures from which the curve had been drawn had

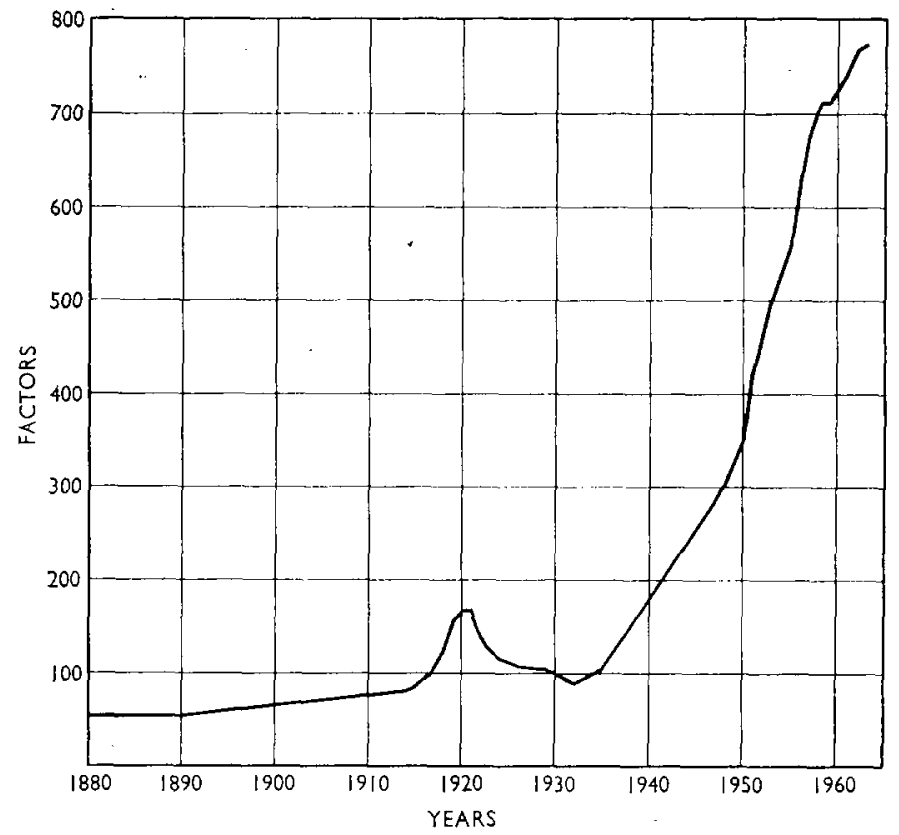

FIG. 35: FACTORS USED FOR COMPARING COSTS OF IRON AND STEEL PLATE GIRDER BRIDGES ON BRITISH RAILWAYS (W.R.)

been determined by the rise and fall in the cost of supply of iron or steel from the mills, fabrication in the workshops and erection on site, due regard being paid to periodical variations in wages. The present-day cost of the original girderwork, subtracted from the cost of the newly designed superstructure, determined the betterment used in adjusting the value of the capital asset.

225. Replying to Mr Pool ( $\$ 135$ ), the Author emphasized the difference between fatigue failure where fractures occurred under stresses caused by cyclic loading which were lower than the ultimate breaking stress, and corrosion fatigue. In the latter, there was a progressive lessening of the sectional area as the products of corrosion, lacking the elastic properties of the steel, broke away under changes of strain. $\mathbf{M r}$ Henry Turner had enlarged on this reasoning. Corrosion fatigue occurred under repetitions of dynamic loading wherever oxygen and moisture were present and conditions were favourable for rusting. Rain, dew, etc, provided just such an environment whenever the protective coat of paint had deteriorated.

226. Referring to $\S 137$, the Author made it clear that the relaxations obtained by 
working to the enhanced permissible stresses in Table 2 would not normally be applicable in strengthening schemes unless it had been established that the work was of a temporary nature needed to extend the life of the bridge over a comparatively short period. Strengthening devised to extend the life almost indefinitely was designed to keep the working stresses below the permissibles specified in B.S.153, but on British Railways the live load would be the heaviest rolling stock likely to use the bridge, with the allowance factor of $1 \cdot 3$. Incidentally, in reply to Mr Turley (\$163); that factor did include the effects of lurching. This loading was less than the 20 units R.A.1 used in the design of new girderwork (Fig. 3), and once the work had been completed, the enhanced permissibles would be used in any assessment and there would again be a margin to take care of the effects of neglect in the future.

227. Commenting on the fitting of bracings as mentioned by $\mathrm{Mr}$ Pool (§ 139), Mr Turley (\$ 165) and Mr Bramall ( $\$ 193)$, the Author placed sway bracings in the same category as laterals. Experience at the River Parrett Bridge ( $\$ 52)$, had demonstrated the deleterious effects of providing inadequate lateral bracing. Where headroom was insufficient for top laterals, heavy knee braces (Fig. 8) performed the function of sway bracing. Laterals in the horizontal plane and sway bracing in the vertical plane were necessary to transmit the horizontally-applied forces from nosing, wind, etc, through the girderwork to the bearings. The amount of lateral oscillation at the centre of a span was a measure of the wracking that the joints between floor members and main girders would be called upon to resist. He considered $\frac{1}{8}$ in. to be about the limit to be tolerated in a 100 -ft span. Tests on the first of the single-track 300 -ft spans in the bridge over the Wye at Chepstow in 1962 had been highly satisfactory. The maximum sideways oscillation was only $\mathbf{0 . 2 0}$ in., and that had been before the span had been tied to its twin alongside. Any span subjected to larger oscillations presented a case for fitting stronger sway and/or lateral bracings, otherwise there would be trouble sooner or later at the nodal points. The friction between bridge timbers and girder flanges was not, he considered, enough to produce an effective form of Vierendeel truss as Mr Turley ( $\$ 166)$ and Mr Bramall ( $(192)$ appeared to have found out. It was, as Mr Webb had inferred, a matter of practice based on experience.

228. Replying to Mr Pool ( $\$ 141$ ), the Author instanced the Royal Albert Bridge as an example where it had proved economical to accept a permanent speed-restriction. The 15 miles/h restriction was imposed on account of the slenderness of the tall pillars supporting the spans on the curved approaches. No doubt, the picking up and dropping of single-line tokens at each end of the bridge called for some reduction of speed in any case, and there had been no move to get rid of the restriction.

\section{REFERENCES}

15. Government of India. Eleventh Report of the Bridge Standards Committee, March 1932. East India Railway Press, Calcutta, 1932.

16. W. E. GeLSON. Some experiments on locomotive springs, with reference to bridge impact-allowances. J. Instn civ. Engrs, vol. 8, no. 5, March 1938, pp. 259-304.

17. W. E. Gelson. Vehicle mechanics of locomotives. Railway Steel Topics, vol. 2, no. 3, 1954, pp. 42-51.

18. T. R. GuRneY. The basis of the revised fatigue clause for B.S.153. Proc. Instn civ. Engrs, vol. 24, April 1963, pp. 519-540.

19. S. WISE. The strength of components repaired by welding. Brit. Weld. J., vol. 6 , no. 8, August 1959 , pp. $345-350$.

20. T. P. O'Sullivan. Strengthening of steel structures under load. Proc. Instn civ. Engrs, vol. 2, pt 1, no. 1, January 1953, pp. 76-95.

21. C. Gribile. Bridge investigation, Ceylon Government Railways, 1949-51, Proc. Instn civ. Engrs, vol. 3, pt. 2, February 1954, pp. 106-157. See also Appendix II, pp. 138-139. 